\title{
REKLAMASI DI TELUK JAKARTA DAN PERUBAHAN SOSIAL PADA MASYARAKAT NELAYAN DI CILINCING JAKARTA UTARA
}

\author{
Reclamation in The Jakarta Bay and Social Change of Fishing \\ Community In the Cilincing of North Jakarta
}

\author{
*Hikmah, Armen Zulham dan Zahri Nasution \\ Balai Besar Riset Sosial Ekonomi Kelautan dan Perikanan \\ Gedung Balitbang KP I Lt. 4 \\ Jalan Pasir Putih Nomor 1 Ancol Timur, Jakarta Utara, Indonesia \\ Telp: (021) 64711583 Fax: 64700924 \\ Diterima tanggal: 22 Januari 2018 Diterima setelah perbaikan: 8 Maret 2018 \\ Disetujui terbit: 6 Juni 2018 \\ *email: hikmah_madani@yahoo.com
}

\begin{abstract}
ABSTRAK
Pembangunan pulau $\mathrm{N}$ di Teluk Jakarta telah mempengaruhi kehidupan sosial ekonomi masyarakat di Cilincing yang terkait dengan perubahan sumber pendapatan, pola aktivitas penangkapan ikan, serta sistem gender pada masyarakat perikanan. Penelitian ini merupakan studi kasus yang menggunakan metode kualitatif. Teknik pengumpulan data menggunakan metode triangulasi guna memperoleh kombinasi data yang akurat. Pemilihan informan melalui teknik bola salju dan dilakukan secara sengaja yaitu memilih orang-orang yang dianggap mengetahui secara detail mengenai gejala perubahan sosial akibat adanya pembangunan reklamasi Teluk Jakarta. Analisis data kualitatif dilakukan secara interaktif dan berlangsung secara terus-menerus sampai tuntas hingga datanya jenuh. Hasil penelitian menggambarkan adanya perubahan sosial yang terjadi akibat adanya pembangunan pulau reklamasi di sekitar Teluk Jakarta antara lain perubahan jenis sumber pendapatan, perubahan pola aktivitas penangkapan, perubahan struktur sosial masyarakat nelayan dan perubahan sistem gender. Tulisan ini merekomendasikan agar pemerintah melakukan asistensi pada masyarakat nelayan yang tidak mampu beradaptasi terhadap perubahan karena pulau reklamasi dengan program mata pencaharian alternatif. Dan bagi masyarakat nelayan yang mampu beradaptasi dengan perubahan yang ada, Harus disiapkan skema bantuan yang jelas, sehingga perekonomian masyarakat nelayan dapat berkembang.
\end{abstract}

Kata Kunci: reklamasi; Teluk Jakarta; Cilincing; perubahan sosial; masyarakat nelayan

\section{ABSTRACT}

The development of the $\mathrm{N}$-island of the Jakarta bay has affected on socio-economic life of the community in Cilincing, especially related to changes in income sources, patterns of fishing activities, and gender systems in fisheries communities. This research was a case study using qualitative method. Data collection techniques use a triangulation method to obtain accuracy data combinations. Informants were selected through snowball techniques and carried out intentionally was chosen for person who were considered understood in detail about the symptoms of social change due to the development of the Jakarta Bay reclamation. Qualitative data analysis was carried out interactively and ended continuously until complete until the data was saturated. Results of the study illustrate that social changes that occur due to the development of reclamation islands around the Bay of Jakarta include changes in the type of income sources, changes in patterns of fishing activities, changes in the social structure of fishing communities and changes in the gender system. This paper recommends that the government do assistant to fishermen communities who are unable to adapt to changes due to reclamation islands with alternative livelihood programs. And for fishing communities who are able to adapt to existing changes, a clear assistance scheme must be prepared, so that the economy of the fishing community can develop.

Keywords: reclamation; Jakarta Bay; cilincing; social change; fishing community 


\section{PENDAHULUAN}

Pembangunan pulau di Teluk Jakarta karena kebijakan reklamasi, berakibat pada beberapa perubahan. Perubahan tersebut mencakup perubahan pada ekosistem di Teluk Jakarta (Puspasari et al., 2017), perubahan oseanografi di dalam Teluk Jakarta (Pranowo et al., 2014), maupun perubahan flora dan fauna pada pesisir Teluk Jakarta (Kusmana, 2014). Perubahan tersebut secara tidak langsung telah mendorong terjadinya perubahan sosial pada masyarakat perikanan di Teluk Jakarta (Zulham et al., 2017).

Studi perubahan sosial telah dilakukan pada berbagai kelompok masyarakat seperti yang dilakukan oleh Bellwood \& Dizon (2013) di Filipina dan Estrada (1999) di Eropa. Pemahaman perubahan sosial tersebut dalam pandangan Parson (1951), harus dilakukan dengan memahami struktur sosial dalam masyarakat tersebut. Struktur sosial adalah tatanan sosial yang membentuk kelompokkelompok sosial dalam masyarakat yang tersusun secara vertikal atau horizontal. Pada pandangan ini kelompok tersebut memiliki identitas untuk berinteraksi dengan lingkungannya. Kelompok sosial pada masyarakat perikanan umumnya terdiri dari nelayan (pemilik kapal dan ABK), pengolah hasil perikanan, maupun pedagang.

Perubahan lingkungan (karena pembangunan pulau reklamasi di Teluk Jakarta) menyebabkan kelompok-kelompok sosial di desa pesisir beradaptasi menghadapi perubahan yang terjadi di Teluk Jakarta. Adaptasi tersebut merupakan bentuk perubahan sosial yang terjadi dalam masyarakat setelah pulau reklamasi di Teluk Jakarta tersebut dibangun. Simandjuntak (2007), mengemukakan perubahan sosial merupakan ciri khas dari masyarakat dan kebudayaan yang berubah. Pada masyarakat modern perubahan itu sangat cepat, sedang dalam masyarakat tradisional sangat lambat. Dalam konteks perubahan sosial akibat pembangunan reklamasi di pesisir Teluk Jakarta, dapat digambarkan sebagai sesuatu akan terjadi setelah jangka waktu tertentu. Fenomena perubahan itu diamati antara sebelum dan sesudah jangka waktu tertentu.

Masyarakat pada Kelurahan Cilincing dengan jumlah penduduk 57.061 jiwa (jumlah nelayan 1.600 orang) merupakan salah satu masyarakat yang menghadapi dinamika perubahan sosial karena pembangunan pulau $\mathrm{N}$ di Teluk Jakarta. Pada satu sisi keberadaan pulau $\mathrm{N}$ melindungi aktivitas nelayan yang berbasis di pinggir muara Cakung Drain, namun pada sisi lain keberadaan pulau $\mathrm{N}$ telah menghilangkan fishing ground nelayan tradisional dan masyarakat Kelurahan Cilincing tidak dapat lagi melakukan budidaya kerang hijau.

Nelayan Kelurahan Cilincing merupakan nelayan tradisional skala kecil. Wilayah penangkapan hanya di sekitar perairan Teluk Jakarta dengan jumlah hari penangkapan ikan 1 hari per trip. Mayoritas nelayan di Cilincing adalah etnis Indramayu dan Bugis. Pada daerah tersebut terdapat juga nelayan dari Pemalang maupun Brebes.Nelayan asal Indramayu hanya menggunakan perahu di bawah 5GT dengan jumlah ABK 2-3 orang. Sedangkan nelayan yang berasal dari etnis Bugis Makassar merupakan pemilik bagan apung dan menggunakan $\mathrm{ABK}$ dari daerah asalnya. Nelayan asal Indramayu rata-rata sudah memiliki rumah dan tinggal menetap di Keluarahan Cilincing. Sementara ABK berasal dari Indramayu tinggal tidak menetap di Kelurahan Cilincing.

Perhatian pemerintah terhadap nelayan di Kelurahan Cilincing cukup besar. Pada tahun 1990 telah dibangun Tempat Pelelang Ikan di muara sungai Cakung drain. Pemerintah juga membangun jalan dan tanggul untuk menahan banjir rob. Secara umum masyarakat pesisir di Kelurahan Cilincing terbentuk oleh kelompokkelompok sosial/etnis yang beragam (heterogen). Ekonomi masyarakat Kelurahan Cilincing tidak hanya dari aktivitas perikanan, namun tergantung pada aktivitas ekonomi pada kawasan Cilincing dan Marunda.

Berdasarkan aktivitas ekonomi tersebut, maka masyarakat di Kelurahan Cilincing dapat dikelompokkan dalam 3 kelompok pelaku usaha, yaitu: 1) pelaku usaha, sebagai pemanfaat langsung sumber daya lingkungan seperti nelayan dan pembudidaya; 2) Pengolah hasil ikan atau hasil laut lainnya seperti pemindang, pengeringan ikan asin, pengolah kerupuk, terasi, dan sebagainya; 3) Penunjang kegiatan ekonomi perikanan seperti pemilik toko atau warung, pemilik bengkel montir atau las, pengusaha angkutan, tukang perahu dan buruh kasar. Kebutuhan tenaga kerja yang tidak membutuhkan keahlian spesifik diperlukan di Cilincing untuk ABK perikanan tangkap. Tulisan ini melihat perubahan sosial yang terjadi pada masyarakat perikanan di Kelurahan Cilincing Jakarta Utara tersebut, yang terus beradaptasi merespon dampak dari pembangunan pulau $\mathrm{N}$ di Teluk Jakarta. 


\section{METODOLOGI}

Tulisan ini didasarkan pada studi kasus pada masyarakat perikanan di Kelurahan Cilincing, Jakarta Utara. Dalam hal ini, studi kasus dapat didefinisikan sebagai studi yang berfokus pada satu kejadian, dan kejadian tersebut dikaji dengan berbagai metode (Stake, 1994 dalam Sitorus, 1998). Hasil penelitian dalam tulisan ini, dijelaskan menggunakan dua pendekatan, yaitu: (a) pendekatan eksplanatif, untuk menjelaskan penyebab gejala sosial pada masyarakat tersebut serta keterkaitan dengan gejala sosial lain (Sitorus, 1998), dan; (b) Pendekatan kualitatif dilakukan untuk menjelaskan hasil penelusuran dalam sistem sosial pada masyarakat nelayan tersebut, terkait dengan perubahan stratifikasi sosial dan sumber pendapatan.

\section{Lokasi Penelitian}

Penelitian ini dilaksanakan di Kampung Bambu, RW 04/RT 05 Kelurahan Cilincing, Kecamatan Cilincing, Jakarta Utara. Pemilihan lokasi penelitian dilakukan secara sengaja (purposive) dengan pertimbangan bahwa Kelurahan Cilincing merupakan salah satu wilayah pesisir yang terkena dampak pembangunan reklamasi di Teluk Jakarta khususnya pembangunan pulau N. Disamping itu, wilayah Jakarta Utara merupakan daerah industri yang pembuangan limbahnya diarahkan ke laut sehingga pemilihan lokasi penelitian dianggap sesuai dengan topik yang diangkat. Penelitian dilaksanakan pada bulan Maret sampai dengan bulan April 2017.

\section{Jenis Data dan Teknik Pengumpulan Data}

Jenis data yang dianalisis adalah data primer, data sekunder, serta diikuti dengan pengamatan langsung di lokasi penelitian. Data yang dikumpulkan meliputi: karakteristik nelayan, perubahan sumber pendapatan, perubahan pola penangkapan ikan, perubahan struktur sosial masyarakat, dan perubahan sistem gender. Pengumpulan data dilakukan dengan metode triangulasi. Metoda ini digunakan untuk memperoleh kombinasi data dan informasi yang akurat.

Dalam penelitian kualitatif data diperoleh dari berbagai sumber, dengan menggunakan teknik pengumpulan data bermacam-macam dan dilakukan secara terus-menerus sampai titik jenuh jawaban yang dibutuhkan (Rosmelawati, 2013). Pengumpulan data primer dengan pendekatan triangulasi dilakukan melalui wawancara mendalam terhadap responden dan informan kunci. Informan yang diwawancara dipilih secara sengaja dan dilakukan dengan teknik snowball sampling. Jumlah informan kunci yang diwawancara sampai dianggap data yang diperoleh telah jenuh. Informan kunci yang dipilih (aparat kelurahan, tokoh masyarakat nelayan, LSM dan lain-lain) dianggap mengetahui secara detail mengenai perubahan sosial karena pembangunan pulau reklamasi Teluk Jakarta khususnya di pulau $\mathrm{N}$.

\section{Analisis Data}

Data hasil wawancara dianalisis secara kuantitatif. Hasil amalisis tersebut menurut Miles dan Huberman (1984) dalam Sugiyono (2009) dieksplorasi secara interaktif. Aktivitas dalam analisis data kualitatif tersebut meliputi data reduction, data display, dan conclusion drawing/ verification.

Data yang telah diperoleh dan dikumpulkan dari lapangan dirangkum dengan memilih hal-hal yang pokok, memfokuskan pada hal-hal yang penting, dan mencari tema serta polanya. Data yang telah direduksi dapat memberikan gambaran yang lebih jelas dan mempermudah untuk pencarian data selanjutnya apabila masih diperlukan (data belum jenuh).

Data disajikan dalam bentuk tabel dan gambar/bagan serta dijelaskan secara deskriptif untuk mempermudah memahami makna data yang berbasis persepsi. Dalam mendeskripsikan setiap bentuk hubungan di kuesioner antara pertanyaan dan jawaban kelompok sasaran secara sederhana digunakan metode analisis deskriptif. Setelah data direduksi dan disajikan, kemudian ditarik sebuah kesimpulan. Kesimpulan tersebut menjawab rumusan masalah yang dijelaskan sejak awal. Basis waktu dalam analisis dampak sebelum dan sesudah adanya pembangunan rekalamasi pulau $\mathrm{N}$ adalah tahun 2015.

\section{HASIL DAN PEMBAHASAN}

\section{Gambaran Umum Masyarakat Nelayan Kelurahan Cilincing}

Data monografi Kelurahan Cilincing tahun 2010 menunjukkan jumlah penduduk di wilayah ini 32.744 jiwa, 11.937 kepala keluarga. Penduduk laki-laki sebanyak 16.529 jiwa dan penduduk perempuan sebanyak 16.215 jiwa. Agama yang 
dianut oleh penduduk di wilayah ini bervariasi. Penduduk yang beragama Islam sebanyak 16.973 jiwa, Kristen sebanyak 11.554 jiwa, Hindu sebanyak 1.962 jiwa, dan Budha sebanyak 2.255 jiwa. Wilayah ini juga dihuni oleh penduduk yang berasal dari berbagai etnik/suku, yaitu Jawa $(35,16 \%)$, Betawi $(27,65 \%)$, Sunda (15,27\%), Batak (3,61\%), Minangkabau $(3,18 \%)$, Melayu $(1,62 \%)$, Bugis $(0,59 \%)$, Madura $(0,57 \%)$, Banten $(0,25 \%)$, dan Banjar $(0,10 \%)$.

Mata pencaharian penduduk di wilayah ini, meliputi: 1.856 orang petani, 2.278 orang nelayan, 346 orang buruh, 3.145 orang pedagang, 2.304 orang karyawan swasta, 2.151 orang pegawai negeri sipil, 2.328 orang tergabung dalam Tentara Nasional Indonesia, 2.251 orang pensiunan, 4.607 orang berwiraswasta, dan 8.608 orang melakukan pekerjaan lainnya. Tingkat pendidikan masyarakat meliputi: 9.525 orang tamatan SD, 8.249 orang tamatan SMP, 6.357 orang tamatan SMA, 2.122 orang tamatan Akademi, dan 4.231 orang tamatan Universitas.

Status kependudukan nelayan di Kelurahan Cilincing pada tahun 2016 terbagi menjadi tiga kelompok, yaitu nelayan yang ber KTP DKI sebanyak $68 \%$, dan lainnya adalah nelayan andon permanen (nelayan yang tinggal dan memiliki rumah di Kelurahan Cilincing namun tidak memiliki KTP DKI) dan nelayan andon musiman (nelayan yang hanya sewaktu-waktu tinggal di kelurahan Cilincing, dan mereka umumnya anak buah kapal yang bekerja di kapal-kapal pemilik di Kelurahan Cilincing). Nelayan andon musiman umumnya berasal dari Tegal, Brebes, Cirebon dan Indramayu.

Nelayan Andon/Fisher's Andon

Nelayan Andon Musiman/Season Andon Fisher's

Nelayan KTP DKI/Fisher's of DKI

\section{Gambar 2. Status Kependudukan Nelayan Kelurahan Cilincing, 2007. \\ Figure 2. Status of the Population Fisher's Cilincing, 2007.}

Sumber: Data sekunder Hasil Penelitian BBRSEKP, 2016/ Source: Research Findings BBRSEKP, 2016

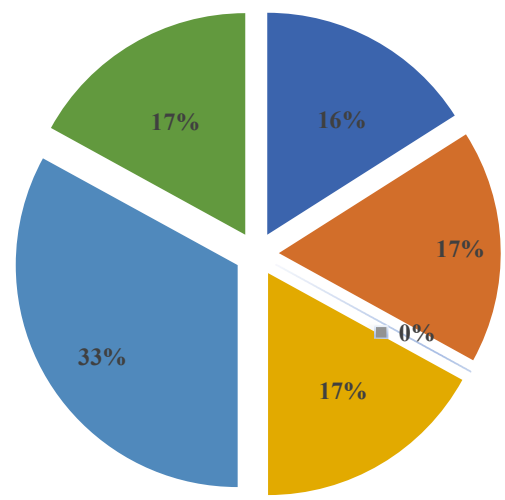

Antara Umur 25-30/Age Among 25-30 Antara Umur 31-35/Age Among 31-35 Antara Umur 41-45/Age Among 41-45

Antara Umur 46-50/Age Among 46-50 Antara Umur 51-55/Age Among 51-55 Antara Umur 56-50/Age Among 56-50

\section{Gambar 3. Kisaran Umur Responden Nelayan} di Kelurahan Cilincing, 2007.

Figure 3. Age Range Fisher's Respondent in Cilincing, 2007.

Keterangan: Jumlah responden 20 orang/

Description: Number of respondents 20 people

Sumber: Data sekunder Hasil Penelitian BBRSEKP, 2016/

Source: Research Findings BBRSEKP, 2016

Kisaran umur responden nelayan lebih dominan berusia antara 51-55 tahun. Usia ini merupakan usia produktif dimana nelayan sudah memiliki pengalaman yang sudah mumpuni dalam hal penangkapan ikan. Dari karakteristik usia responden didapatkan informasi tentang gejala perubahan sosial yang terjadi pasca pembangunan pulau reklamasi.

\section{Perubahan Sosial Masyarakat Nelayan Cilincing}

\section{Perubahan Sumber Pendapatan}

Tabel 1, memberi gambaran tentang, sumber pendapatan responden di Kelurahan Cilincing yang berasal dari berbagai sumber, seperti: usaha penangkapan ikan, budidaya kerang hijau, pengupas kulit kerang, pengolah ikan, pedagang ikan, jasa sewa kontrakan, jasa sewa perahu, buruh bangunan, buruh pabrik, dan buruh cuci. Tabel tersebut menunjukkan terjadi perubahan sosial terhadap sumber pendapatan masyakarat nelayan di Cilincing sejak adanya pembangunan pulau reklamasi. Sumber pendapatan pada sumber pendapatan dari budidaya kerang hijau hilang. Bahkan banyak tenaga kerja perempuan kehilangan pekerjaan mereka membantu sebagai menopang kehidupan keluarganya karena sumber pendapatan dari usaha kerang hijau tidak ada lagi. 
Tabel 1. Sumber Pendapatan Masayarakat Nelayan di Kelurahan Cilincing, 2007. Table 1. Revenue Source Fishing Community in the Village of Cilincing, 2007.

\begin{tabular}{|c|c|c|}
\hline $\begin{array}{l}\text { Sumber Pendapatan Responden/ } \\
\text { Sources of Income of Respondents }\end{array}$ & $\begin{array}{l}\text { Sebelum Reklamasi/ } \\
\text { Before Reclamation }\end{array}$ & $\begin{array}{l}\text { Sesudah Reklamasi/ } \\
\text { After Reclamation }\end{array}$ \\
\hline $\begin{array}{l}\text { Pendapatan dari usaha penangkapan ikan//ncome } \\
\text { from fishing }\end{array}$ & Ada/there is & Ada/there is \\
\hline $\begin{array}{l}\text { Pendapatan dari usaha perikanan budidaya kerang } \\
\text { hijau/Income from the business of Aquaculture } \\
\text { Shellfish Green }\end{array}$ & Ada/there is & Tidak ada/No \\
\hline $\begin{array}{l}\text { Pendapatan dari usaha pengupas kulit kerang/ } \\
\text { Income from business peeler shells }\end{array}$ & Ada/there is & Tidak ada/No \\
\hline $\begin{array}{l}\text { Pendapatan dari usaha pengolah ikan/ Income from } \\
\text { business processing fish }\end{array}$ & Ada/there is & Ada/there is \\
\hline $\begin{array}{l}\text { Pendapatan dari usaha pedagang ikan/ income from } \\
\text { business merchants fish }\end{array}$ & Ada/there is & Ada/there is \\
\hline $\begin{array}{l}\text { Pendapatan dari usaha jasa sewa kontrakan/ } \\
\text { Income from businesses rental services for rent }\end{array}$ & Ada/there is & Ada/there is \\
\hline $\begin{array}{l}\text { Pendapatan dari usaha jasa sewa perahu/ Income } \\
\text { from business services boat rental }\end{array}$ & Tidak ada/ No & Ada/there is \\
\hline $\begin{array}{l}\text { Pendapatan dari usaha buruh bangunan/ Revenue } \\
\text { from business construction worker }\end{array}$ & Tidak ada/ No & ada \\
\hline $\begin{array}{l}\text { Pendapatan dari usaha buruh pabrik/ Income from } \\
\text { venture factory workers }\end{array}$ & $\begin{array}{l}\text { Ada, tidak dominan/ there } \\
\text { are, no dominant }\end{array}$ & $\begin{array}{l}\text { Ada, dominan/ there } \\
\text { are, dominant }\end{array}$ \\
\hline $\begin{array}{l}\text { Pendapatan dari usaha buruh cuci/ Revenue from } \\
\text { businesses laundry worker }\end{array}$ & Tidak ada/No & Ada/there is \\
\hline
\end{tabular}

\section{Perubahan Pola Aktivitas Penangkapan}

Kegiatan reklamasi secara langsung telah mempengaruhi mata pencaharian nelayan tradisional di Teluk Jakarta (Ramadhan et al., 2016). Ragam mata pencaharian masyarakat Kelurahan Cilincing yang menggantungkan hidupnya pada bidang perikanan sebelum adanya pulau reklamasi adalah sebagai nelayan, pembudidaya kerang hijau, pengolah ikan asin dan kerang hijau, pedagang ikan dan udang. Pulau reklamasi di Teluk Jakarta telah mengindikasikan terjadi perubahan pola mata pencaharian masayarakat yang memanfaatkan perairan sekitar Teluk Jakarta.

Menurut hasil penelitian Sampono (2013), sebanyak 43\% dari responden di Kelurahan Cilincing memiliki persepsi bahwa adanya reklamasi akan berdampak terhadap perubahan daerah penangkapan ikan (DPI). Meskipun tidak semua responden sepakat bahwa reklamasi akan berdampak merugikan terhadap DPI, namun menurut Van Berkel et al. (2012) kegiatan reklamasi akan berdampak terhadap kegiatan pelabuhan perikanan dan daerah penangkapan ikan di Teluk Jakarta.
Berdasarkan hasil survei, nelayan Kelurahan Cilincing pada umumnya melakukan aktifitas penangkapan dengan menggunakan alat tangkap payang, mini purse seine, gillnet, bagan dan dogol, sementara aktifitas budidaya laut adalah budidaya kerang hijau. Lebih lanjut, Sampono (2013) mengemukakan bahwa hasil overlay terhadap daerah penangkapan ikan (DPI) dengan rencana pembangunan pulau reklamasi pulau $\mathrm{O}$ dan $\mathrm{P}$ maka daerah penangkapan ikan yang akan terkena dampak langsung akibat kegiatan reklamasi adalah nelayan yang menggunakan alat tangkap bagan dan pembudidaya kerang hijau. Bagan yang digunakan di sekitar Teluk Jakarta umumnya bagan tancap dan ada juga bagan apung.

Perubahan sosial pada aktivitas penangkapan ikan akibat pembangunan pulau reklamasi adalah terjadinya perubahan daerah penangkapan ikan (DPI). Reklamasi akan langsung berdampak terhadap DPI karena lokasi pulau baru sebagai hasil reklamasi, akan menghilangkan wilayah perairan yang selama ini menjadi DPI bagi nelayan. Hilangnya wilayah perairan tersebut berganti menjadi daratan (pulau) dan akan memaksa nelayan untuk menemukan DPI baru yang lebih jauh ke arah lautan bebas. 


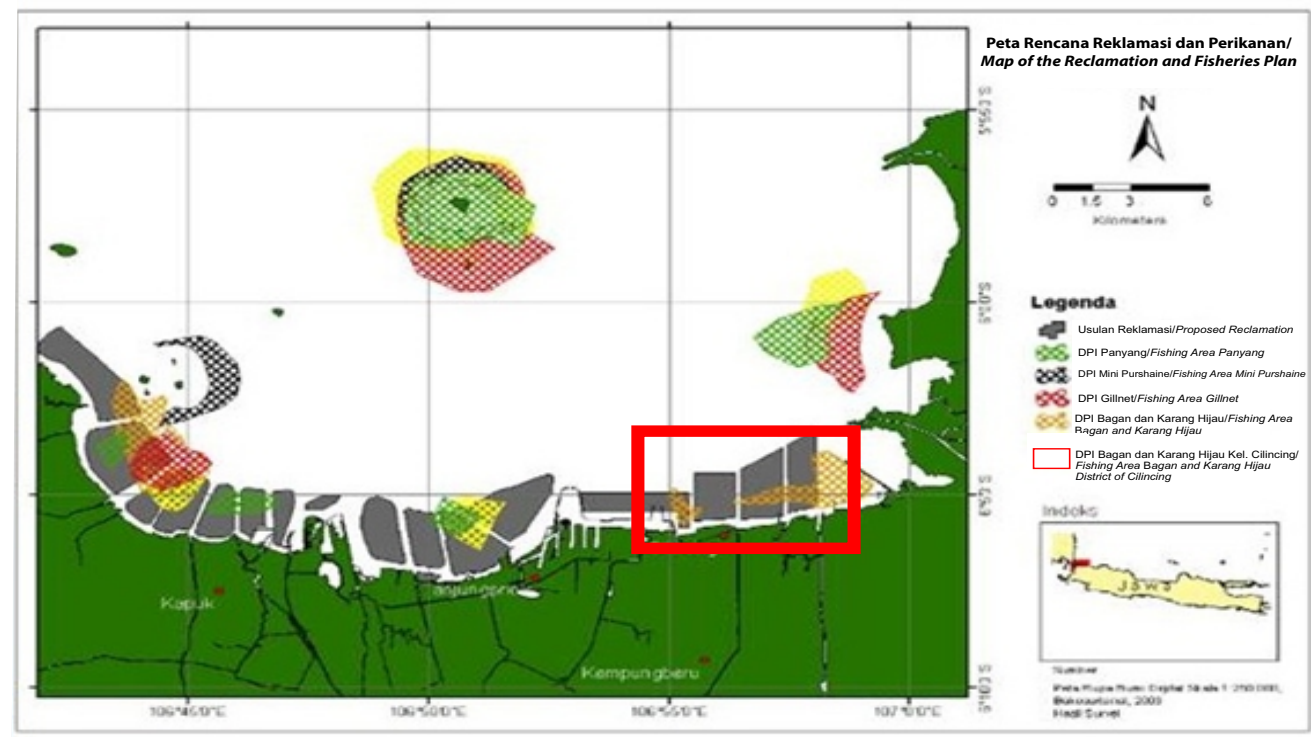

Gambar 2. Peta overlay Daerah Penangkapan Ikan di Kelurahan Cilincing. Figure 2. Map Overlay Fishing Area in Cilincing Village.

Sumber: Data sekunder Hasil penelitian Sampono (2013)/Source: Secondery data Sampono (2013)

Pada Tabel 1 dapat dilihat bahwa sebelum adanya reklamasi, daerah Cilincing merupakan salah satu sentra budidaya kerang hijau. Komoditas kerang hijau menjadi salah satu pilihan nelayan budidaya di Teluk Jakarta khususnya di Desa Kamal Muara dan Cilincing. Hingga tahun 2009, total nelayan budidaya kerang hijau di Kelurahan Cilincing mencapai 1.626 orang dengan total produksi mencapai 31.100 ton (Jury et al., 2011). Namun dengan adanya kegiatan reklamasi tahun 2015 lokasi budidaya kerang hijau sudah sejak lama eksis menjadi hilang.

Tabel 1. Perubahan Sosial Akibat Pembangunan Pulau Rekalamasi Terhadap Mata Pencaharian, 2007. Table 1. Symptoms of Social Changes Dur to The Development of Island Reclamation to Livelihood Patterns, 2007.

\begin{tabular}{|c|c|c|}
\hline $\begin{array}{c}\text { Mata Pencaharian/ } \\
\text { Livelihood }\end{array}$ & $\begin{array}{l}\text { Dampak Reklamasi/ } \\
\text { Impact of Reclamation }\end{array}$ & $\begin{array}{l}\text { Perubahan Sosial/ } \\
\text { Social Change }\end{array}$ \\
\hline Nelayan/Fishers' & $\begin{array}{l}\text { - Daerah penangkapan ikan lebih jauh/ } \\
\text { The fishing area is further away } \\
\text { - Terganggunya daerah penangkapan } \\
\text { ikan akibat adanya hilir mudiknya } \\
\text { kapal-kapal ke pelabuhan Marunda/ } \\
\text { Disturbed fishing grounds due to the } \\
\text { up and down of the ships to the port } \\
\text { of Marunda }\end{array}$ & $\begin{array}{l}\text { - Adaptasi nelayan dengan Perubahan } \\
\text { daerah penangkapan ikan yang lebih } \\
\text { jauh lagi di Muara Gembong/ Adaptation of } \\
\text { fishers with new fishing area change even } \\
\text { further in Muara Gembong } \\
\text { - Memanfaatkan daerah penangkapan ikan } \\
\text { di sekitar Pulau Reklamasi/ Utilize the } \\
\text { fishing area around Reclamation Island }\end{array}$ \\
\hline $\begin{array}{l}\text { Pembudidaya Kerang } \\
\text { Hijau/ Green shellfish } \\
\text { cuture }\end{array}$ & $\begin{array}{l}\text { - Hilangnya lahan budidaya kerang } \\
\text { hijau/Loss of green shellfish } \\
\text { Maricuture }\end{array}$ & $\begin{array}{l}\text { - Pembudidaya kerang hijau beralih profesi } \\
\text { sebagai pedagang ikan, pedagang alat- } \\
\text { alat perikanan, pengolah ikan, buruh, } \\
\text { tukang ojek/ Green shellfish cultivators } \\
\text { shift professions as fish traders, traders } \\
\text { of fishery equipment, fish processors, } \\
\text { laborers, motorcycle taxi drivers }\end{array}$ \\
\hline $\begin{array}{l}\text { Pedagang Ikan dan udang/ } \\
\text { Fish and shrimp Traders }\end{array}$ & $\begin{array}{l}\text { - Berkuranya pasokan ikan, udang } \\
\text { sebagai akibat dari berkurangnya } \\
\text { produksi ikan hasil tangkapan } \\
\text { nelayan dan pembudidaya/ Declining } \\
\text { supply of fish, shrimp as a result } \\
\text { of the collapsed fish production of } \\
\text { fisher's and cultivators }\end{array}$ & $\begin{array}{l}\text { - Membentuk jaringan sosial yang lebih luas } \\
\text { untuk mendapatkan pasokan ikan dari } \\
\text { desa lain/ Establish a wider social network } \\
\text { to get fish supplies from other villages }\end{array}$ \\
\hline
\end{tabular}




\section{Lanjutan Tabel 1/Continue Table 1}

\begin{tabular}{|c|c|c|}
\hline $\begin{array}{c}\text { Mata Pencaharian/ } \\
\text { Livelihood }\end{array}$ & $\begin{array}{l}\text { Dampak Reklamasi/ } \\
\text { Impact of Reclamation }\end{array}$ & $\begin{array}{l}\text { Perubahan Sosial/ } \\
\text { Social Change }\end{array}$ \\
\hline $\begin{array}{l}\text { Pengolah Kerang Hijau/ } \\
\text { green mussel processing }\end{array}$ & $\begin{array}{l}\text { - Hilangnya usaha pengolahan } \\
\text { kerang hijau akibat hilangnya lahan } \\
\text { budidaya/ Loss of green shell } \\
\text { processing business due to loss of } \\
\text { cultivated land }\end{array}$ & $\begin{array}{l}\text { - Adaptasi mencari sumber mata } \\
\text { pencaharian baru/ Adaptation to find new } \\
\text { sources of livelihood } \\
\text { - Tetap melakukan pengolahan kerang } \\
\text { dengan memperluas jaringan sosial } \\
\text { dengan pembudidaya di luar desa/ Keep } \\
\text { doing shell processing by expanding social } \\
\text { network with cultivators outside the village. }\end{array}$ \\
\hline $\begin{array}{l}\text { Pengolah ikan asin/ } \\
\text { Processing of salted fish }\end{array}$ & $\begin{array}{l}\text { - Berkurangnya omset pengolahan } \\
\text { ikan asin karena menurunnya bahan } \\
\text { baku/ Reduced turnover of salted } \\
\text { fish processing due to declining raw } \\
\text { materials }\end{array}$ & $\begin{array}{l}\text { - Membentuk jaringan sosial yang lebih luas } \\
\text { untuk mendapatkan pasokan ikan dari } \\
\text { nelayan bagan desa lain/ Establish a wider } \\
\text { social network to get fish supplies from } \\
\text { other village chart fishers } \\
\text { - Mencari sumber alternative pencaharian } \\
\text { lain/ Looking for alternative sources of } \\
\text { livelihood }\end{array}$ \\
\hline $\begin{array}{l}\text { Anak Buah Kapal/The crew } \\
\text { fishers' }\end{array}$ & - Kehilangan pekerjaan/ loss of a job & $\begin{array}{l}\text { - Menganggur/ I-dle } \\
\text { - Pindah ke desa lain/ Move to another } \\
\text { village } \\
\text { - Ganti pekerjaan (pekerja serabutan } \\
\text { kuli angkut, pekerja bangunan dan } \\
\text { lain sebagainya)/ Change jobs (casual } \\
\text { laborers, construction workers, etc). }\end{array}$ \\
\hline $\begin{array}{l}\text { Buruh pengolah ikan asin/ } \\
\text { Salted fish processing } \\
\text { workers }\end{array}$ & - Kehilangan pekerjaan/loss of a job & $\begin{array}{l}\text { - Menganggur/ Move to another village } \\
\text { - Ganti pekerjaan (kuli angkut, pekerja } \\
\text { bangunan dan lain sebagainya) /Change } \\
\text { jobs (casual laborers, construction } \\
\text { workers, etc). }\end{array}$ \\
\hline $\begin{array}{l}\text { Buruh Pengolah kerang } \\
\text { hijau/Worker Green shell } \\
\text { Processing }\end{array}$ & - Kehilangan pekerjaan/ loss of a job & $\begin{array}{l}\text { - Ganti pekerjaan (pembantu rumah tangga, } \\
\text { buruh pabrik dan lain sebagainya)/ } \\
\text { Change jobs (casual laborers, construction } \\
\text { workers, etc). }\end{array}$ \\
\hline
\end{tabular}

\section{Perubahan Struktur sosial}

Struktur sosial yang terbentuk dalam kehidupan nelayan dibangun oleh faktor-faktor yang kompleks. Faktor-faktor tersebut tidak hanya berkaitan dengan fluktuasi musimikan, keterbatasan sumberdaya manusia, keterbatasan modal, serta jaringan perdagangan ikan yang eksploitatif, tetapi juga dampak negatif modernisasi perikanan. Sesuai dengan pendapat Saleha (2013), konsep struktur sosial dalam penelitian ini dipahami sebagai konsep yang membentuk susunan pelapisan dan pola hubungan antara orang-orang yang terikat dalam suatu sistem sosial yang dibatasi atau dikendalikan oleh norma-norma atau pola-pola tingkah laku yang disepakati bersama. Kajian struktur sosial ini mengandung konsep stratifikasi (pelapisan), pembedaan status dan peran, relasi kerja serta mobilitas (pergerakan) antar lapisan.
Hasil penelitian pada masyarakat nelayan di Kelurahan Cilincing menunjukkan bahwa struktur masyarakat nelayan yang terbentuk berdasarkan penguasaan dan kepemilikan modal serta alat produksi. Pada masyarakat nelayan di cilincing, pelapisan sosial yang terbentuk terdiri atas tiga strata yaitu Pemilik modal (bos), nelayan pemilik kapal dengan status sosial sedang/menengah dan nelayan buruh (ABK).

Pemilik modal yang juga berfungsi sebagai pedagang atau bakul, merupakan strata pertama dengan status sosial yang paling tinggi. Mereka itu memiliki modal finansial dalam skala besar dan alat produksi yang lengkap. Pemilik modal yang sering disebut "bos" oleh para nelayan ini menyediakan modal untuk kebutuhan operasional penangkapan dan jika diperlukan juga menyediakan kapal dan alat tangkap yang dibutuhkan oleh nelayan yang bekerjasama dengannya. Umumnya pemilik 
modal tidak terlibat langsung dengan kegiatan penangkapan. Pemilik modal juga merangkap fungsi sebagai pedagang pengumpul yang membeli ikan hasil tangkapan dan kemudian menjualnya kembali melalui proses pelelangan di TPI, ataupun melalui jaringan pemasaran sendiri ke luar daerah.

Nelayan pemilik kapal merupakan strata kedua dengan status sosial sedang/ menengah. Nelayan ini memiliki alat produksi berupa kapal dan alat tangkap, tetapi biasanya tidak memiliki cukup modal finansial untuk kebutuhan operasional melaut sehingga adakalanya masih memerlukan bantuan pinjaman modal maupun input produksi dalam bentuk natura dari ponggawa. Nelayan pemilik ini masih terlibat langsung melakukan operasi penangkapan di laut dengan dibantu oleh nelayan buruh ataupun tanpa nelayan buruh. Strata ketiga yang merupakan status sosial paling rendah adalah nelayan buruh. Nelayan buruh ini memiliki modal tenaga sebagai sumbangan dalam struktur kerja kelompok, tetapi tidak memiliki modal finansial, kapal atau alat tangkap.

Jaringan sosial terjalin atas dasar hubungan antar keterkaitan individu. Keterkaitan individu dalam hubungan sosial merupakan pencerminan manusia sebagai makhluk sosial. Hubungan antar individu tersebut membentuk jaringan sosial yang sekaligus merefleksikan terjadinya pengelompokan sosial dalam masyarakat (Kusnadi, 2000).

Keberadaan masyarakat nelayan dalam suatu jaringan sosial merupakan bentuk kerjasama kolektif dalam penjualan hasil tangkap di Kelurahan Cilincing. Jaringan sosial pada masyarakat nelayan di Kelurahan Cilincing terbentuk berdasarkan kesamaan kebutuhan yang saling menguntungkan antar pelaku usaha perikanan. Jaringan sosial ini juga terjadi pada masyarakat nelayan di Sei Jang Kecamatan Bukit Bestari Kota Tanjung Pinang (Muniruzzaman, 2015).

Jaringan sosial yang dibangun mulai dari proses mendapatkan hasil tangkapan sampai pada memasarkan hasil tangkapan tersebut. Jaringan sosial ini juga terjadi antara nelayan lokal dengan nelayan pendatang (andon). Nelayan andon tinggal dan beraktivtas di atas perahu. Di Cilincing, nelayan andon terkenal dengan sebutan RCTI (Rombongan Cirebon, Tegal dan Indramayu). Nelayan andon tidak memiliki rumah sehingga untuk menjamin usaha mereka agar dapat bertahan, mereka membangun relasi dengan nelayan lokal yang ada di wilayahnya. Nelayan andon memiliki langgan/ bos untuk memasarkan hasil tangkapannya. Hal ini membuat nelayan andon tetap bertahan ditengah keterbatasan yang dimiliki.

Bagi nelayan andon atau lokal di Cilincing, langgan/bos memiliki peranan penting, tidak hanya berperan dalam rantai pemasaran tetapi juga juga berperan pada aspek kehidupan yang lebih luas. Langgan turut andil menyediakan modal baik modal investasi maupun modal biaya operasional. Selain itu langgan juga meyediakan kebutuhan pokok nelayan pada saat panceklik, kredit informal, dan kebutuhan lainnya. Hal ini yang menjadikan ikatan bagi kliennya untuk menjual hasil tangkapannya ke langgan Di satu sisi nelayan sangat membutuhkan pembeli hasil tangkapannya, dan disisi lain langgan membutuhkan hasil tangkapan ikan untuk mereka jual. Bertemunya dua kelompok sosial dengan suatu kebutuhan bersama menyebabkan terjadinya proses saling mempengaruhi dalam berinterkasi. Hubungan dan interaksi sosial yang terjalin tersebut telah berjalan selama puluhan tahun secara terusmenerus melahirkan sistem sosial budaya yang berkelanjutan dan menjamin kehidupan masyarakat nelayan di Cilincing.

Pola hubungan interaksi sosial yang ada di Cilincing salah satunya adalah hubungan sosial antara nelayan ABK dengan nahkoda. Beberapa bentuk relasi yang ada di pesisir Teluk Jakarta yaitu:

1. Nelayan pemilik dengan pedagang pengumpul. Relasi ini dibangun untuk menjamin kepastian ikan hasil tangkapan terjual semua. Keuntungan yang diterima oleh nelayan adalah nelayan tidak perlu lagi memasarkan ikan hasil tangkapan karena sudah ada yang langsung memasarkan ikannya.

2. Nelayan pemilik dengan pedagang saprokan. Relasi ini dibangun untuk menjamin kepastian input produksi seperti ransum dan BBM. Keuntungan yang diterima oleh nelayan adalah nelayan tidak perlu mempersiapkan uang tunai karena dapat berhutang kepada pedagang sembako dan BBM. Biasanya pedagang memberikan batas pengambilan sembako atau BBM sebanyak 2-3 kali hutang.

3. Pemilik modal dengan nahkoda. Relasi terjalin antara juragan pemilik modal kapal dengan Nahkoda yang didasarkan adanya adanya hubungan saling membutuhkan. Juragan pemilik kapal membutuhkan nahkoda untuk menjalankan asetnya, sedangkan nahkoda membutuhkan kapal dan biaya operasional untuk melakukan aktivitas mengakap ikan di 
laut. Biasanya interaksi ini terjadi atas dasar kepercayaan. Aturan main yang ada dalam relasi ini adalah sistem bagi hasil.

4. Nelayan ABK dengan Pemilk kapal. Relasi yang terjalin antara nelayan ABK dan pemilik kapal didasari kebutuhan masing-masing karena ABK tidak memiliki asset kapal sehingga tetap dapat melaut sedangkan pemilik kapal tidak lagi kesulitan mencari ABK sehingga kapalnya bisa menghasilkan uang. Relasi sosial antara nelayan ABK dan pemilik kapal biasanya menimbulkan konsekuensi hak dan kewajiban sehingga melahirkan sistem bagi hasil.

5. Relasi sosial antara pedagang pengumpul dengan pedagang pengecer. Relasi ini biasanya didasarkan pada kebutuhan masingmasing pihak. Pedagang pengumpul ikan menginginkan ikan yang dimilikinya cepat laku terjual, sedangkan pedagang pengecer menginginkan mendapatkan ikan sehingga dapat memasarkan ikan. Relasi antara pedagang pengumpul dan pedagang pengecer ini tidak hanya dilakukan antara mereka yang kenal dan tinggal di lokasi yang sama; tetapi lebih didasarkan pada rasa saling percaya (trust) yang terbangun karena seringnya mereka bertemu dan berinteraksi. Pada umumnya ikan yang dibawa oleh pedagang pengecer tidak selalu dibayar tunai karena sudah ada rasa saling percaya. Besarnya piutang yang diberikan oleh pedagang pengumpul berbeda-beda, namun informasi dari salah satu pedagang pengumpul yang diwawancarai mengaku besaran piutang dari nelayan dan pedagang pengecer umumnya berjumlah di atas seratus juta rupiah.

6. Relasi sosial antara pedagang pengumpul ikan dengan pengolah ikan asin. Relasi antara pedagang pengumpul dan pengolah ikan asin memiliki kemiripan dengan relasi pedagang pengumpul dan pengecer. Biasanya relasi mereka didasari rasa saling percaya karena sudah sering berinteraksi.

Dampak pembangunan pulau reklamasi terhadap pola relasi dan jaringan sosial antara pemilik kapal dengan nahkoda, nahkoda dengan ABK, pemilik dengan pedagang tidak terlihat. Meskipun terjadi penurunan produksi, nelayan pemilik, nahkoda dan ABK tetap melakukan aktivitas penangkapan seperti sebelum adanya pembangunan pulau reklamasi. Jaringan sosial yang telah terjalin selama bertahun-tahun tetap seperti sebelum adanya reklamasi.

Hal itu berbeda dengan pola interaksi antara pembudidaya/peternak dan pengolah kerang hijau. Interaksi yang terjalin diantara mereka menjadi terputus karena peternak kerang hijau tidak lagi melakukan budidaya kerang hijau dan memasok ke pengolah akibat adanya pembangunan pulau reklamasi tersebut. Pola adaptasi yang dilakukan oleh peternak kerang hijau yaitu melakukan ternak di wilayah lain dan ada pula yang melakukan aktivitas sebagai nelayan tangkap atau pedagang.

Nahkoda memiliki relasi dengan pemilikkapal. Nahkoda memiliki relasi dengan langgan warung. Pemilik kapal memiliki relasi dengan langgan ikan. Relasi yang ada terbentuk berdasarkan aspek kepentingan. Nahkoda berkepentingan dengan ABK karena terikat dalam sebuah ikatan kerja secara informal. Relasi yang terbentuk memenuhi aspek ekonomi kebutuhan. Selain itu ada beberapa relasi yang terjalin antara nahkoda dan ABK bersadarkan kekerabatan ada pula yang terjalin bersadarkan kedekatan pertemanan.

Nahkoda membutuhkan ABK untuk kegiatan penangkapan ikan dan ABK membutuhkan nahkoda sebagai sandaran dalam mencari nafkah. Nahkoda yang tidak memiliki perahu, memiliki relasi langsung dengan pemilik kapal. Dalam hal ini pemilik kapal mempercayakan kapal yang dimilikinya untuk diusahakan oleh nahkoda. Ikatan kerja yang terjadi adalah ikatan antara pemilik kapal dan nahkoda, sedangkan ABK memiliki hubungan langsung dengan nahkoda dan tidak memiliki hubungan langsung dengan pemilik kapal. Pada usaha penangkapan, nahkoda yang memiliki kapal akan berhubungan kepada langgan ikan sebagai tempat menjual ikan dan langgan warung tempat membeli/meminjam bahan bahan operasional. Jika memiliki hutang, maka relasi yang terjadi menjadi terikat, yaitu adanya kesepakatan bahwa tetap melakukan kesepakatan selama masih ada ikatan hutang. Bentuk relasi dan jaringan ini juga berlaku untuk nelayan lokal dan pendatang (andon). Nelayan andon tidak memiliki lahan untuk bagan di Cilincing, namun nelayan andon memiliki akses terhadap pemilik lahan di Cilincing. Nelayan andon menyandarkan perahu di bagan yang dimiliki oleh langgan. Bagan terdapat disepanjang alur keluarmasuk kapal di Cilincing.

Pola hubungan dan interaksi ini juga terbentuk antara peternak kerang hijau dengan pengolah kerang hijau. Peternak kerang hijau 
memiliki relasi dengan pekerja ternak kerang hijau dan pengolah kerang hijau. Pengolah kerang hijau mempunyai hubungan interaksi dengan pekerja pengolah kerang hijau yang mana didominasi oleh perempuan.

\section{Perubahan Sistem Gender}

Sistem gender adalah sistem pembagian kerja secara seksual (the division of labor by sex) dalam masyarakat nelayan, yang didasarkan pada kebudayaan yang ada. Dengan kata lain, sistem gender merupakan konstruksi sosial dari masyarakat nelayan yang terbentuk sebagai hasil evolutif dari suatu proses dialektika antara manusia, lingkungan, dan kebudayaannya. Sebagai produk budaya, sistem gender diwariskan secara sosial dari generasi ke generasi (Afriyani, 2011).

\section{Sistem gender masyarakat nelayan di Kelurahan Cilincing terpola dan menjadi stereotype bahwa pekerjaan yang terkait dengan penangkapan di laut merupakan ranah kaum laki-laki, sedangkan pekerjaan yang berada di wilayah darat yang berhubungan dengan aktivitas domestik seperti memasak, mencuci dan lain sebagainya adalah ranah kerja kaum perempuan. Afriyani (2011) mengungkapkan bahwa pekerjaan di laut, seperti melakukan kegiatan penangkapan, menjadi ranah laki-laki karena karakteristik pekerjaan ini membutuhkan kemampuan fisik yang kuat, kecepatan bertindak, dan berisiko tinggi. Dengan kemampuan fisik yang berbeda, kaum perempuan menangani pekerjaan-pekerjaan di darat, seperti mengurus tanggung jawab domestik, serta aktivitas sosial-budaya dan ekonomi.}

Lebih lanjut Afriyani (2011) mengemukakan bahwa kaum perempuan memiliki cukup banyak waktu untuk menyelesaikan tanggungjawab pekerjaan tersebut. Sebagian besar aktivitas perekonomian di kawasan pesisir melibatkan kaum perempuan dan sistem pembagian kerja tersebut telah menempatkan kaum perempuan sebagai "penguasa aktivitas ekonomi pesisir". Dampak dari sistem pembagian kerja ini adalah kaum perempuan mendominasi dalam urusan ekonomi rumah tangga dan pengambilan keputusan penting di rumah tangganya. Dengan demikian, kaum perempuan tidak berposisi sebagai "suplemen" tetapi bersifat "komplemen" dalam menjaga kelangsungan hidup rumah tangganya.

Dampak pembangunan pulau reklamasi mengindikasikan terjadinya gejala perubahan struktur sosial ekonomi masyarakat nelayan tradisional di Kelurahan Cilincing, tidak terkecuali sistem gender, meskipun dampak yang ditimbulkan tidak semuanya negatif. Aktivitas ekonomi yang melibatkan kaum perempuan di Kelurahan Cilincing adalah pengolahan hasil perikanan seperti pengolahan ikan asin dan pengolahan kerang hijau. Karena pendapatan suami yang tidak menentu membuat wanita nelayan memiliki kegiatan lain di luar aktivitas domestik (kegiatan harian seorang wanita pada umumnya) dan aktivitas sosial lain. Peran perempuan nelayan tidak hanya sebatas menjaga dan mengurus anak, membersihkan rumah dan sebagainya melainkan secara nyata sudah terlibat dalam kegiatan ekonomi langsung. Wanita nelayan umumnya bekerja yang langsung menghasilkan uang, di antaranya sistem kerja upah langsung dan jual beli, sehingga para wanita nelayan bisa langsung mendapatkan uang setelah mereka bekerja. Ada pula ibu-ibu dan anak-anak nelayan membantu ekonomi rumah tangganya dengan bekerja sebagai buruh pengolah/membersihkan kerang dengan upah Rp.3000,- per ember, namun sekarang sudah jarang ada aktifitas. Artinya, pembangunan pulau rekalamasi memberikan dampak negative terhadap akses permepuan nelayan untuk memanfaatkan sumberdaya khususnya sumberdaya kerrang hijau.

\section{KESIMPULAN DAN IMPLIKASI KEBIJAKAN}

\section{Kesimpulan}

Karakteristik Nelayan Kelurahan Cilincing merupakan nelayan tradisional yang melakukan penangkapan ikan skala kecil. Wilayah penangkapan hanya di sekitar perairan Teluk Jakarta dengan jumlah hari penangkapan hanya 1 hari per trip. Mayoritas nelayan di Cilincing adalah suku Jawa (Indramayu,) Bugis, Ujung Pandang. Nelayan Indramayu biasanya hanya menggunakan perahu dibawah 5GT dengan jumlah ABK 2-3 orang. Status kependudukan nelayan di Kelurahan Cilincing pada tahun 2016 terbagi menjadi tiga kelompok yaitu nelayan yang ber KTP DKI, nelayan andon permanen dan nelayan andon musiman. Nelayan andon permanen adalah nelayan yang tinggal dan memiliki rumah di Kelurahan Cilincing namun tidak memiliki KTP DKI.

Pembangunan pulau reklamasi menimbulkan dampak pada perubahan sosial antara lain perubahan sumber pendapatan, pola mata pencaharian, struktur sosial, dan sistem gender 
masyarakat nelayan skala kecil yang melakukan kegiatan penangkapan di sekitar perairan Teluk Jakarta. Perubahan sosial ini membuat mereka melakukan adaptasi baik dengan beralih ke sumber mata pencaharian baru, maupun memperluas jaringan dan relasi sosial.

\section{Implikasi Kebijakan}

Permasalahan tentang dampak sosial akibat pembangunan pulau reklamasi terhadap masyarakat perikanan di Cilincing perlu segera dicarikan solusinya, terutama terhadap masyarakat nelayan yang tidak mampu beradaptasi dengan perubahan yang ada. Pemerintah harus melakukan pendampingan tentang mata pencaharian alternatif pada nelayan tanpa melakukan relokasi. Bagi masyarakat nelayan yang mempunyai pola adaptasi dengan adanya pembangunan pulau reklamasi harus didukung dengan berbagai skema bantuan agar perubahan sosial tersebut memberi manfaat yang besar dalam pembangunan ekonomi di Cilincing.

\section{UCAPAN TERIMAKASIH}

Penulis mengucapkan terimakasih kepada Balai Besar Riset Sosial Ekonomi Kelautan dan Perikanan (BBRSEKP) yang telah memfasilitasi pelaksanaan kegiatan penelitian ini, rekanrekan peneliti yang survey lapang dalam rangka pengumpulan data terkait dengan penelitian tentang reklamasi di Teluk Jakarta pada Tahun 2017. Terima kasih juga kepada key informan di Cilincing. Selain itu, ucapan terima kasih juga kepada segenap tim redaksi yang telah memberikan masukan dan arahan untuk penyempurnaan tulisan ini.

\section{DAFTAR PUSTAKA}

Afriayani, A.Y. 2011. Sosioligi Masyarakat Nelayan. http:// www.bppp-tegal.com/web/index.php/ artikel/ manajemen/122-sosiologi-masyarakat-nelayan. Diakes Pada tanggal 22 Mei 2017.

Bellwood, P. dan E. Dizon. 2013. The Batanes Islands, Their First Observers and Previous Archeology in (Bellwood and Dizon eds). 4000 Years of Migration and Cultural Exchanges. ANU Press. Australia. hal. 2 - 8 .

Berkel,V. J., M. Jury, T. Foster, J. Dusik, B. Wiryawan, L. Salaki, N. Chans, dan S. Pans. 2012. Jakarta Bay Recommendation Paper by DHI Water \& Environement. Publikasi Danida ESP2.
Kementerian Lingkungan Hidup Republik Indonesia. 222 hal.

Estrada, E.M. 1999. Social and Economic Changes and Players in Rural Areasof the South of Europe. IESA-CSIC, Cordoba-Spain.Retrieved from: http://creativecommons.org/licences/by-nd/2.0/fr/ deed.fr.

Jury, M., S. Pans, T. Golingi, dan B. Wiryawan. 2011. Kajian Dampak Lingkungan Pengembangan Pesisir Teluk Jakarta (Rapid Environmental Assessment Coastal Development in Jakarta Bay) by $\mathrm{DHI}$ Water\&Environment. Publikasi Danida ESP2. Kementerian Lingkungan Hidup Republik Indonesia.143 hal.

Kusnadi, 2004. Mengatasi Kemiskinan Nelayan Jawa Timur: Pendekatan Terintegrasi, Bagaimana Harus Memulai, dalam Kusnadi (Penyunting),Polemik Kemiskinan Nelayan, Yogyakarta: Pembaharuan.

Kusmana, C. 2014. Konservasi dan Rehabilitasi Mangrove di Wilayah DKI Jakarta. Fakultas Kehutanan IPB. hal.10.

Muniruzzaman. 2015. Eksistensi Masyarakat Nelayan dalam Mengatasi Kemiskinan di Kelurahan Sei Jang Kecamatan Bukit Bestari Kota Tanjungpinang. Naskah Publikasi. Universitas Maritim Raja Ali Haji. Program Studi Sosiologi Fakultas IImu Sosial dan IImu Politik Tanjung Pinang.

Parsons, T. 1951. The Social System. Collier Mc. Millan Ltd. The Free Press of Glenco. London.

Pranowo, W.S, G. Pramono, M. Hutomo, A. Nontji dan I. Maufikoh. 2014. Karakteristik Oseanografi Ekoregion Laut Provinsi DKI Jakarta. Dalam Poernomo, A. B. Sulistyo, S. Wirasantosa dan I.S Brodjonegoro (eds) Dinamika Teluk Jakarta: Analisis Prediksi Dampak Pembangunan Tanggul Laut Teluk Jakarta (Jakarta Giant Sea Wall). hal. 55 - 68. IPB Press.

Puspasari, S., S.T. Hartati, dan R.F. Anggawangsa. 2017. Analisis Dampak Reklamasi Terhadap Lingkungan dan Perikanan di Teluk Jakarta. Jurnal Kebijakan Perikanan Indonesia. Vol. 9(2): 85-94.

Ramadhan, A., M. Firdaus, R.A. Wijaya, dan I. Mulyawan. 2016. Estimasi Kerugian Nelayan dan Pembudidaya Ikan Akibat Reklamasi Di Teluk Jakarta. Jurnal Sosek KP. Vol. 11(1) : 1-11.

Rosmelawati. 2013. Manajemen Pengawasan Pendidikan Agama Islam Sekolah Menengah Pertama di Kabupaten Bandung (Studi Deskriptif di Kelompok 
Kerja Pengawas (Pokjawas) Kementerian Agama Kabupaten Bandung, Universitas Pendidikan Indonesia.repository.upi.edu. perpustakaan.upi. edu. hal. 58.

Saleha, Q. 2013. Kajian Struktur Sosial dalam Nelayan di Pesisir Kota Balikpapan. BULETIN PSP. Vol. 21(1) : 67-75.

Sampono, N. 2013. Analisis Kebijakan dalam Mengatasi Dampak Reklamasi Terhadap Kegiatan Perikanan Pantai di Teluk Jakarta. Tesis. Institut Pertanian Bogor. 126 hal.

Simandjuntak, B. 2007. Sosiologi Pembangunan. Bina IImu. Jakarta.

Sitorus, M.T.F. 1998. Penelitian Kualitatif Suatu Perkenalan. Kelompok Dokumentasi IImu Sosial. Institut Pertanian Bogor.

Sugiyono. 2009. Metode Penelitian Kualitatif. Alfabeta. Bandung.

Zulham, A., Z. Nasution, S.A. Pranowo, Hikmah, M. Firdaus, B.V.I. Yanti, dan Nurlaili. 2017. Perubahan Sosial dalam Masyarakat Perikanan Karena Kebijakan Reklamasi. Laporan Penelitian. BBPSEKP. Jakarta. 